\title{
Anti-laminin autoantibodies in collagen vascular diseases: the use of adequate controls in studies of autoimmune responses to laminin
}

\author{
D E Cohen, L D Kaufman, A A Varma, J R Seibold, M Stiller, B L Gruber
}

Division of Allergy,

Rheumatology, and

Clinical Immunology,

State University of

New York at Stony

Brook,

Stony Brook,

NY, USA

D E Cohen ${ }^{\star}$

L D Kaufman

B L Gruber

The Ronald $O$

Perelman Department

of Dermatology, *

New York University

Medical Center,

New York,

NY, USA

$M$ Stiller

Department of

Preventative Medicine,

State University of

New York at Stony

Brook,

Stony Brook,

NY, USA

A A Varma

Division of

Rheumatology,

UMDNJ Robert Wood

Johnson Medical

School,

New Brunswick,

NJ, USA

J R Seibold

Correspondence to:

Dr B L Gruber,

Dr B L Gruber,

Division of Allergy,
Rheumatology, and Clinical

Immunology,

T-16 Room 040

T-16 Room 040 ,
State University of New York

at Stony Brook,

Stony Brook,

NY 11794-8161, USA.

Accepted for publication

30 November 1993

\begin{abstract}
Objectives-To determine the significance of anti-laminin antibodies in patients with collagen vascular diseases using a large control population of normal individuals. Methods-Anti-laminin antibodies of IgG isotypes were determined using an ELISA assay in a population consisting of 73 patients with systemic sclerosis, 10 with urticarial vasculitis, five with leukocytoclastic vasculitis, 13 with giant cell arteritis, and eight with dermatomyositis. Sera from 134 healthy individuals served as controls.
\end{abstract}

Results-Only eight sera in the systemic sclerosis group, one in the leukocytoclastic group and one in the giant cell arteritis group were abnormal. No other sera were abnormal.

Conclusion-These data contradict previous studies using smaller numbers of controls. The necessity for an adequate control population to define abnormal when comparing immune responses among groups is frequently underemphasised in rheumatological studies.

(Ann Rheum Dis 1994; 53: 191-193)

Reports of both humoral and cell-mediated immunity to the basement membrane component laminin in infectious and autoimmune diseases have been published since laminin was initially characterised in $1979 .{ }^{1-5}$ The presence of anti-laminin antibodies was recently reported in patients with Raynaud's phenomenon and scleroderma by Gabrielli et al. ${ }^{6-8}$ Laminin, a cysteine rich $(1000 \mathrm{Kd})$ glycoprotein found ubiquitously in basement membranes is composed of one $(400 \mathrm{Kd})$ alpha chain and three $(200 \mathrm{Kd})$ beta chains arranged in a crucifix structure. ${ }^{9}$ Laminin acts as an epithelial cell attachment factor and has affinity for type IV collagen, heparin, and heparan sulphate proteoglycan. ${ }^{9-11}$ By investigating the prevalence of $\mathrm{IgG}$ anti-laminin antibodies in the sera of patients with connective tissue diseases by immunoassay, we emphasised the use of an adequate control population and valid statistical analyses of data. We report the data on a total of 109 patients with systemic sclerosis and vasculitis.

\section{Methods}

Our patient population consisted of 73 individuals with systemic sclerosis (defined by the American Rheumatism Association criteria), ${ }^{12}$ all associated with Raynaud's phenomenon, 10 patients with urticarial vasculitis, five with leukocytoclastic vasculitis, 13 with giant cell arteritis and eight patients with dermatomyositis. Sera from 134 healthy individuals served as controls.

We employed an enzyme linked immunosorbent assay (ELISA). Laminin isolated from Engelbreth-Holm-Swarm sarcoma (Bethesda Research Laboratories) was diluted in $0.02 \mathrm{M}$ carbonate buffer ( $\mathrm{pH} \mathrm{9.6)}$ to a concentration of $2 \mu \mathrm{g} / \mathrm{ml}$. A total of $100 \mu \mathrm{l}$ was placed in each of 96 wells of flat bottom polystyrene microELISA plates (Immulon 2 plates, Dynatech labs, Alexandra, VA) and incubated for 48 hours at $4^{\circ} \mathrm{C}$. Wells were serially washed three times with $200 \mu$ l of phosphate buffered saline (PBS) containing $0.05 \%$ Tween 20 and $0.02 \% \mathrm{NaNO}_{3}(\mathrm{pH} 7 \cdot 4$ ), at three minute intervals. The binding of laminin to the polystyrene microELISA plates was confirmed using commercially obtained monoclonal antibodies to laminin (Telios, San Diego, CA). A secondary alkaline phosphatase labelled antibody (Cooper Biomedical, Malverne, PA) was strongly reactive within minutes. Sera were diluted in PBS-Tween in a 1:10 ratio, and 100 $\mu l$ were placed in triplicate wells for controls and duplicate wells for test sera. Plates were incubated for two hours at room temperature. Different blocking agents were used to reduce background reactivity including ovalbumin, bovine serum albumin, and human serum albumin (each at $1 \mathrm{mg} / \mathrm{ml}$ ). After three serial washings, $100 \mu \mathrm{l}$ of alkaline phosphataselabelled goat anti-human IgG (Cooper Biomedical, Malvern, PA) diluted 1:1000 in PBS-Tween was added to each well and incubated for two hours. Plates were again washed and $100 \mu$ l of p-nitrophenyl phosphate disodium (Sigma, St Louis, MO) substrate was added and incubated in the dark for one hour. The plates were then read in a microELISA reader (Dynatech labs, Alexandra, VA) at $405 \mathrm{~nm}$.

\section{Results}

Data from control sera were analysed using all three readings from each triplicate independently. Inter and intra group correlations are shown in the table. A histogram of the control data (figure) shows distribution that was considerably shifted to the left with a leptokortic (tented) shape. The results from this large group of controls were not normally 
Inter-individual and replicate standard deviations and interclass correlation coefficients of control and test sera. Values are for optical density readings at 405 nanometers

\begin{tabular}{lclll}
\hline Group & Sample size & $\begin{array}{l}\text { Inter-individual } \\
\text { standard } \\
\text { deviation }\end{array}$ & $\begin{array}{l}\text { Standard } \\
\text { deviation } \\
\text { of replicates }\end{array}$ & $\begin{array}{l}\text { Intraclass } \\
\text { correlation } \\
\text { coefficient }\end{array}$ \\
\hline Controls & 134 & $258 \cdot 27$ & $23 \cdot 36$ & 0.99 \\
Urticarial vasculitis & 10 & $125 \cdot 12$ & $18 \cdot 57$ & 0.98 \\
Leukocytoclastic vasculitis & 5 & $347 \cdot 42$ & $27 \cdot 28$ & 0.99 \\
Giant cell arteritis & 13 & $109 \cdot 64$ & $10 \cdot 62$ & 0.99 \\
Dermatomyositis & 8 & $182 \cdot 65$ & $14 \cdot 07$ & 0.99 \\
Raynaud's phenomenon & 73 & $75 \cdot 75$ & $12 \cdot 22$ & 0.97 \\
\hline
\end{tabular}

$\star$ By designating inter-individual standard deviation as $\left(S_{1}\right)$ and standard deviation of replicates as $\left(S_{e}\right)$, the intraclass correlation coefficient $(r)$ is defined as: $r=S_{1}^{2} /\left(S_{1}^{2}+S_{e}^{2}\right)$.

distributed, so mean and standard deviation could not be simply applied to determine a 'cutoff value' for normalcy. Thus for comparative purposes, log transformation of the control data or designation of a percentile of the non-normal control data had to be applied. For simplicity, the latter technique was used. Using the 90 th percentile, one that would favour false positivity, we identified only eight sera 'above normal' in patients with systemic sclerosis $(10.9 \%)$. These eight patients had no distinguishing clinical features. No sera from patients with urticarial vasculitis or giant cell arteritis were abnormal. One serum in the leukocytoclastic vasculitis group (20\%) and one in the dermatomyositis group $(12.5 \%)$ were above normal. These results did not significantly change after altering the blocking reagents used on the ELISA plates. The healthy controls were re-questioned regarding possible Raynaud's disease or related disorders without appreciable change in these results.

\section{Discussion}

These data contrast with those of Gabrielli et $a l,^{6}$ and reported that $48 \%$ of their patients with systemic sclerosis had 'significantly elevated levels' of anti-laminin antibodies.
They failed to mention whether the distribution of the 38 control sera justified their definition of abnormal as greater than the mean plus two standard deviations. Recently Gabrielli et $a l^{13}$ demonstrated that the immunoreactive epitope of mouse laminin recognised by these autoantibodies is the terminal disaccharide, galactosyl ( $\alpha$ 1-3) galactose. Gabrielli used only 30 controls to determine the prevalence of reactivity to galactosyl $(\alpha 1-3)$ galactose in systemic sclerosis $(55 \cdot 3 \%)$. Normal controls demonstrated reactivity albeit at a lower titre attributed to potential crossreactivity to similar disaccharide linkages found in dietary antigens and bacterial flora. ${ }^{17}$ Gabrielli $^{8}{ }^{14}$ recently reported similar results using a larger control group $(n=85)$ but again no information was provided on the distribution of the normal data. Thus the validity of using two standard deviations above the mean as abnormal remains doubtful.

An adequate control population is essential when defining an abnormal immune response using a quantitative analytical method such as an ELISA. Analysis of a large number of control sera proved that the distribution of controls greatly overlapped with the test sera, and few if any sera could be considered abnormal. It is imperative to plot a large number of control values to determine their fit into a normal curve. While standard deviation is frequently used as a method of separating normal and abnormal values, without this curve it may be invalid, diminishing the significance of any conclusions.

Our data underscore an important question; are anti-laminin antibodies of pathogenic significance in connective tissue diseases? The results on 134 healthy controls indicate that the degree of immune responsiveness to mouse laminin is quite variable. These data were

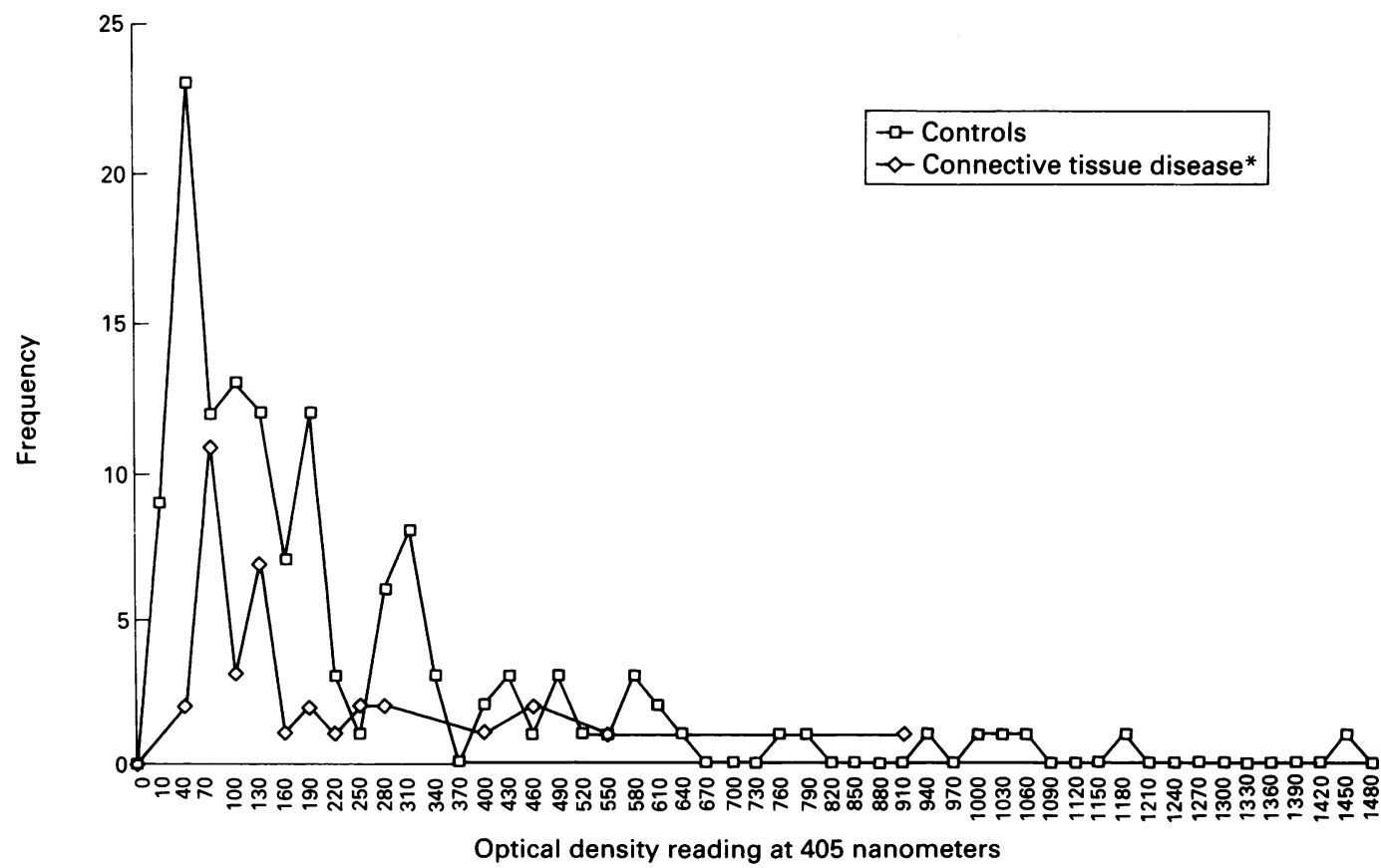

*Urticarial vasculitis, leukocytoclastic vasculitis, giant cell arteritis, dermatomyositis

Anti-laminin antibody titres in healthy controls and patients with connective tissue diseases. 
consistent regardless of the methodology employed including varying incubation times, substrate ratios, blocking agents, serum dilution, antibody dilution, or type of microtitre plates. It is unlikely that mere technical differences in the performance of assays underlie our inability to corroborate previously published data. ${ }^{4}{ }^{6}$ Our data support the conclusion of Bernard et $a l^{15}$ that hidden antigenic loci in the basement membrane lattice may be exposed during normal metabolic processes with the resulting production of anti-basement membrane antibodies in subjects with no clinically discernible immunological disorder.

Our findings suggest the need for caution when defining 'abnormal' antibody responses in patients with immunologically-mediated diseases. We conclude that there is insufficient evidence to support the theory that an abnormal humoral immune response to laminin exists in patients with systemic sclerosis.

1 Timpl R, Rohde H, Robey R G, Rennard S, Foidart J M, Martin G R. A glycoprotein from basement membranes. 7 Biol Chem 1979; 254: 9933-7.

2 Avila J L, Rojas M, Rieber M. Antibodies to laminin in American cutaneous leishmaniasis. Infect Immun 1984, 43: $402-6$.

3 Szarfman A, Terranova V P, Rennard S I, Foidart J M Scheinman J I, Martin G R. Antibodies to Laminin in Cheinman J I, Martin G R. Antibodies to Lamis

4 Avila J L, Rojas M, Velazquez-Avila G, Rieber $M$ Antibodies to basement membrane proteins nidogen and laminin in sera from streptococcal-related diseases and juvenile rheumatoid arthritis patients. Clin Exp Immunol 1987; 70: 555-61.

5 Mackel A M, DeLustro F, DeLustro B, Pedenberg H H, LeRoy E C. Immune response to connective tissue components of the basement membrane. Connect Tiss Res 1982; 10: 333-43.

6 Gabrielli A, Montroni M, Pupoli S, Caniglia M L DeLustro F, Danieli G. A retrospective study of antibodies against basement membrane antigens (type IV collagen and laminin) in patients with primary and secondary raynaud's phenomenon. Arthritis Rheum 1988; 31: $1432-6$.

7 Galili U Abnormal expression of $\alpha$-galactosyl epitopes in man. A trigger for autoimmune processes? Lancet 1989; man. A

8 Gabrielli A, Candela M, Pisani E, Hermann K, Wieslander J, Krieg T. Antibodies against galactosyl $(\alpha 1-3)$ galactose epitopes in systemic sclerosis (scleroderma). Clin Exp Rheum 1992; 10: 31-36.

9 Woodly D T. The molecular organization of basemen membrane. In: Uitto J, Perejda A J, eds. Connective tissue disease molecular pathology of the extracellular matrix, 1 st ed. New York: Marcel Dekker, 1987, 141

10 Bronner-Fraser $M$, Lallier T. A monoclonal antibody against a laminin-heparan sulfate proteoglycan complex perturbs cranial neural crest migration in vivo. $f$ Cell Biol 1988; 106: $1321-9$.

11 Roberts D D, Wewer U M, Liotta L A, Ginsberg V. Laminin dependent and laminin independent adhesion of human dependent and laminin independent adhesion of human

12 Subcommittee for Scleroderma Criteria of the American Rheumatism Association Diagnostic and Therapeutic Criteria Committee: Preliminary criteria for the classification of systemic sclerosis (scleroderma). Arthritis Rheum 1982; 25: 1271-7.

13 Gabrielli A, Candela M, Ricciatti A M, Caniglia M L Antibodies to mouse laminin in patients with systemic sclerosis recognizing galactosyl (alpha 1-3)-galactose epitopes. Clin Exp Immunol 1991; 86: 367-73.

14 Gabrielli A, Leoni P, Hermann K, Danieli G, Weislander J, Kreig T. Antibodies against galactosyl $(\alpha 1-3)$ galactose in connective tissue diseases. Arthritis Rheum 1991; 24: 375.

15 Bernard A, Lauwerys R, Mahieu P, Foidart J M. Antilaminin membrane antibodies in the serum of healthy subjects. $N$ Engl f Med 1986; 314: 1456-7. 